\section{CHLOROFORM ANAESTHESIA.}

THE administration of chloroform is a subject that is of personal and direct interest to everyone in this present age of civilisation. Sooner or later either we ourselves or those dear to us gladly accept the relief from suffering that is offered, and that chloroform shall be given so that no unavoidable risk is run is a necessity that forces itself on our attention.

That much remains to be done in the direction of safety is only too evident. We confess to perusing the diagram of the yearly increasing death-rate from chloroform on p. I4 of Dr. Waller's lecture with a feeling of horror, and that is deepened when we read the instances given of such deaths, and supplemented by others which have come to our knowledge independently, where chloroform has been given for a trifling operation to an otherwise healthy patient, and where the phrase "Death from cardiac syncope" has acted as an anæsthetic to the conscience of the ignorant and careless anæsthetist. It is plain that some vital factor in the problem of safe chloroform administration has been overlooked, and what this consists in is readily seen when it is pointed out to us. The student of anæsthetics is taught to regard most carefully the minor details of the process; the observation of the state of the pulse and the condition of the conjunctival reflex is reduced to a fine art, but the most important detail of all, the amount of chloroform administered, is dismissed with the remark, made in our hearing by a professional anæsthetist, "I judge of the dose of chloroform by the effect ${ }^{2}$ on the patient "!!! Yet if strychnine or arsenic were given without a measured dose, the folly of the proceeding would be manifest, and the possibility of such a remark, made by one who had spent some time in the study of the subject, shows at least that this study had been misapplied.

To replace ignorance of knowledge it is, however, necessary to do more than talk, and the lecture now under review gives an outline of the research that has been carried on in the physiological laboratory of the University of London on chloroform anæsthesia. It was apparent that there was a great lack of quantitative measurement in the process, and the first step consisted in obtaining a ready and accurate method for the estimation of the percentage of chloroform in air, and this was accomplished by the "densimetric" method. It then became possible readily to ascertain :-

(I) What percentage of chloroform in the inspired air was sufficient to cause anæsthesia.

(2) What percentage of chloroform caused death.

(3) How this death was brought about.

(4) By taking the percentage of chloroform in the expired air as well as in the inspired, together with the amount of air breathed, to measure the total quantity of chloroform used in any experiment.

Proceeding in this quantitative way, it was found that though death from too much chloroform can occur in either of two ways, yet, so far as the experiments lead us, neither way can occur when chloroform is given regularly in a percentage not greater than 2, and so before we can claim that a healthy patient has died from "idiosyncrasy" or "cardiac syncope" it is incumbent on us to show that we have not given him too much chloroform, and to ascertain that the cause of death (in at least the great majority of cases) arises from this easily remediable source, and not from some mysterious accident, is a very great advance towards safety.

We shall await the results of further observations on the human subject with interest, as well as the records of the use of the Dubois apparatus, which appears to be well adapted for clinical use. But meanwhile the facts here recorded merit the most careful consideration, and clearly point out the lines on which further research must be carried out.

1 A Lecture on the Administration of Chloroform to Man and the Higher Animals. Delivered in the University of London on October 3,1903 , by A. D. Waller, M.D., F.R S.

${ }^{2}$ By a curious mental process this anæsthetist, when the patient dies, does not consider that too much chloroform has been given, but that death bas occurred from "idiosyncrasy"!

NC. 1798 , voL. 69]
THE FIRST INTERNATIONAL CONGRESS FOR SCHOOL HYGIENE.

THAT it should be possible to hold an international congress on a subject which a few years ago had but little attention paid to it shows the enormous strides which have been made in the knowledge of the hygiene of children attending schools.

The first International Congress of School Hygiene was held at Nuremberg from April 4 to 9 , and the credit for starting the congress must be given to Prof. Griesbach, the president of the "Allegemein deutschen Vereins für Schulgesundheitspflege." The energy and determination with which Prof. Griesbach overcame all obstacles are proved by the fact that every European country, except Italy and Turkey, was represented at the congress, and in addition to these European countries America and Japan were also represented.

The congress was opened formally by Prince Ludwig Ferdinand of Bavaria, and the work of the congress was carried on in sections. How extensive the work of the congress was may be gathered from the fact that there were seven sections. The first dealt with school buildings and the furnishing of the school-room, the second with the hygiene of residential schools, with the methods of hygienic investigation and research in schools, and with the physiology and psychology of educational methods and work.

The third section dealt with instruction in hygiene for teachers and scholars, the fourth with physical education and training in personal hygiene, the fifth with contagious diseases, ill-health, and conditions affecting attendance at school. The sixth section dealt with special schools, including those for the feeble-minded, the blind, deaf, dumb, cripple, invalid and exceptional children, and the seventh with out of school hygiene, holiday camps and schools, the relation of the home and the school, and the hygiene of the teaching profession.

The sectional meetings were held in the Royal Industrial School, a building well adapted for such a purpose. An exhibition of apparatus necessary for school purposes was held in the same building. Excellent arrangements had been made for the accommodation of those attending the congress, and also for obtaining information. Nor had the social side of the congress been neglected, and every facility was given to visitors to see those things in which they took the greatest interest.

Great Britain was represented by a committee with representatives from various societies interested in education and hygiene, with Sir Lauder Brunton as president.

The next International Congress of School Hygiene will be held in London in 1907 , and Sir Lauder Brunton has been elected president of that congress.

\section{UNIVERSITY AND EDUCATIONAL INTELLIGENCE.}

At the graduation ceremony at the University of Edinburgh on April 9 the honorary degree of LL.D. was conferred on Prof. Alexander Macalister, F.R.S.

Dr. Rose, H.M. Consul at Stuttgart, continues his account of German technical education in No. 603 of the miscellaneous series of the diplomatic and consular reports issued by the Foreign Office. The recent report is on technical schools for special branches of the metal industries. Dr. Rose finds that in Germany for certain special branches of the metal and other industries the practical instruction given to apprentices in the workshops of factories is often incomplete and not progressively arranged, and the theoretical instruction given in evening and Sunday continuation schools is generally insufficient and not even obligatory in all cases. At the special technical schools for these industries the instruction is complete and progressively arranged, practice and theory being carefully and judiciously combined. As the schools, moreover, are situated in the midst of the industries they are intended to promote, they are kept in the closest possible touch with the actual and progressive requirements of factory methods and processes. The report gives full accounts of the courses of instruction, the hours, the preliminary knowledge expected of students, 
and the examinations at each of the twelve technical schools for special branches of the metal industries which have been established in Germany.

THE thirty-ninth annual catalogue of the Massachusetts Institute of Technology at Boston gives full particulars of the multitudinous courses of instruction provided and of the complete laboratory accommodation and equipment available for every branch of scientific technology. In addition to the opportunities for advanced study and investigation connected with the Graduate School of Engineering Research, the institute now offers excellent facilities for purely scientific research in all its laboratories. For research work in physical chemistry and sanitary science two new laboratories devoted exclusively to these subjects have been established during the past year. Researches in the research laboratory of physical chemistry are carried on in part by a staff of research assistants and associates and in part by graduate students working under the direction of the professors connected with the subjects of theoretical o: physical chemistry. A number of advanced lecture courses are offered by the members of the laboratory staff. $\mathrm{B} y$ the generosity of an anonymous donor the institute has recently established upon land specially secured for the purpose a sanitary research laboratory and sewage experiment station, provided with facilities for demonstration of the more important methods employed on a large and a small scale for the purification of sewage and water, and in connection therewith well equipped sanitary, chemical, and bacteriological laboratories.

The Department of Agriculture and Technical Instruction for Ireland has issued, in the miscellaneous series of its Bulletins, a report on some features of American education, by Mr. Robert Blair, the assistant secretary in respect of technical instruction to the department. Mr. Blair was a member of the Mosely Education Commission, and part of this report appears in the recent conjoint report of the commission. Some interesting statistics collected by Mr. Blair as to the openings for students trained in American technical institutions are summarised in the report. It appears that in the Westinghouse shops and offices 160 college-bred men are engaged, out of a total of 10,000 employees. At the Carnegie Steel Works, where there are 7000 hands, there were about roo technically trained men 7 of the 23 leading officers being college graduates. Of I1 8 engineers on the staff of the Rapid Transit Railroad Commissioners of New York City, who are constructing a city underground railway, 84 per cent. had been college students; of 75 petty officers, 58 per cent. were college trained. In the Baldwin Locomotive Works, 43 ; on the Pennsylvania railway lines west of Pittsburg, 52 " nearly all being graduates."; at the Schenectady works of the General Electric Co., 264 ; the Illinois Central Railroad Co. employ 200 men who are " either graduates of a technical institution or have had some training in that line"; and a similar proportion is true in the case of the employees of the Baltimore and Ohio Railway. Facts such as these are the best proof of the belief of the American people in higher education, and it is to be hoped that British employers of labour will soon follow a similar course. Given suitable openings for qualified technical students in this country, and the increase in the number of students in our colleges would soon be apparent.

\section{SOCIETIES AND ACADEMIES.}

\section{LoNDON.}

Royal Society, February, 18.- "Atmospherical Radioactivity in High Latitudes." By George C. Simpson, B.Sc., 185 I Exhibition Scholar, Owens College, Manchester. Communicated by Arthur Schuster, F.R.S.

In Igor Elster and Geitel discovered a radio-active gas in the earth's atmosphere, and developed a method of detecting it, also an arbitrary standard by which it can be measured. In this paper the author gives the results of a series of measurements carried out on Elster and Geitel's plan at the village of Karasjok, Lapland. The measurements were made three times a day, and continued uninterrupted for four weeks, from November 23 to December 19, 1903, during which time the sun did not rise above the horizon.

$$
\text { No. } 1798, \text { vOL. 69] }
$$

The chief result obtained is the very high value which the radio-activity attains, the mean value for the month $(\mathrm{A}=\mathrm{I02})$ being nearly six times, and the maximum value $(A=432)$ nearly seven times greater than the corresponding values found for mid-Germany by Elster and Geitel.

An analysis of the results shows that the means of the morning and afternoon observations are very near one another ( 87 and 88 respectively), while the mean of those for the evening is very much higher (131), thus showing a daily period.

The effect of the different meteorological elements is fully investigated, but no connection can be detected between the radio-activity and the height of the barometer or the temperature, although the latter extends over the wide range from $-35^{\circ}$ to $+2.5^{\circ} \mathrm{C}$. On the contrary, the amount of cloud does appear to have an influence, the radio-activity for no clouds being $A=I 30$, for detached clouds $A=107$, for completely overcast sky $A=76$. Measurements of the potential gradient, which were made by a self-registering electrometer concurrently with those of the radio-activity, show no direct relation between the two. The aurora also appears to exert no influence on the radio-activity.

These results are of peculiar interest owing to the northerly position of the place of observation $\left(69^{\circ} 20^{\prime} \mathrm{N}\right.$. and $25^{\circ} 30^{\prime}$ E.), and will throw some light on the geographical distribution of atmospheric radio-activity. The hard frozen state of the ground, with its covering of snow for more than roo miles round, are uniform conditions which should help to a proper understanding of the source of the radio-active emanation in the air.

March io.- "On Electric Resistance Thermometry at the Temperature of Boiling Hydrogen." 1 By Prof.' James Dewar, M.A., LL.D., F.R.S.

In his Bakerian lecture the author adverted shortly to some results obtained in low temperature resistance thermometry, and gave a table (Roy. Soc. Proc., vol. 1xviii. p. 363) of numerical values deduced from experimental observations for some of the more prominent metal resistance thermometers. In the present communication the experimental records of eight additional electric resistance thermometers are given, and the results of the observations on all the resistance thermometers used during the investigations are collected and compared.

Two facts seem to result from this inquiry, viz. (I) that the resistance of an unalloyed metal continually diminishes with temperature and in each case appears to approach to a definite asymptotic value below which no further lowering of the temperature seems to reduce it; and (2) that the parabolic connection between temperature and resistance is no longer tenable at very low temperatures.

Of the different thermometers constructed on the electric resistance principle, fifteen were serviceable throughout the investigations; the others broke or failed from various causes. The metals employed were platinum, gold, silver, copper, palladium, iron, nickel, and two alloys, platinumrhodium and German silver. Every endeavour was made to attain the highest purity in the samples. In the Bakerian lecture a table (Roy. Soc. Proc., vol. Ixviii. p. 363) was given containing the constants of seven of these thermometers, and in the present paper similar results are tabulated for the remaining eight.

The observed resistances, after all corrections were made, were reduced both by Callendar's and by Dickson's methods, and the results are in close accord.

Platinum, gold, silver, and copper show a remarkable agreement between the two methods of reduction. In the platinum and gold groups the centigrade temperature, at which the resistance would vanish, rises with the purity. This is still seen in copper, but something of the reverse appears in the case of silver. However, the general rule is again apparent in palladium.

It is also remarkable that in the cases of all the purest metals examined, their resistances calculated by either method of reduction vanish at temperatures above $-273^{\circ} \mathrm{C}$. As measurers of temperature gold and silver seem to be the best metals.

As a matter of interest, one line in the table which accompanies the paper records the ratio in which the 1 In continuation of Art. 3 of the Bakerian Lecture (Rov Soc.Proc. vol. Ixviii. p. $3^{60 .}$ ) 